\title{
Dominant and Gender-Specific Tendencies in the Use of Discourse Markers: Insights from EFL Learners
}

\author{
Mahboobeh Tavakoli ${ }^{1} \&$ Amin Karimnia ${ }^{2, *}$ \\ ${ }^{1}$ Department of English Language, Marvdasht Branch, Islamic Azad University, Iran. \\ ${ }^{2}$ Department of English Language, Fasa Branch, Islamic Azad University, Iran. \\ *Correspondence: Department of English Language, Fasa Branch, Islamic Azad University, Iran. E-mail: \\ aminkarimnia@yahoo.com
}

Received: May 26, 2017

Accepted: June 15, 2017 Online Published: June 24, 2017

doi:10.5430/wjel.v7n2p1

URL: https://doi.org/10.5430/wjel.v7n2p1

\begin{abstract}
This study followed two objectives: it primarily investigated the types of discourse markers (DMs) used in the spoken language of Iranian advanced EFL learners, and then explored the possible impact of gender on the participants' use of DMs. To this end, 40 male and female EFL learners selected from an English language institute participated in this study. The data were gathered through class observations. The researchers used Fraser's taxonomy of DMs and Fung's category of interpersonal DMs as the theoretical framework of the study. To analyze the data descriptive and inferential statistics were used. Results of the frequency test revealed that "and" was the most commonly used elaborative DM, whereas "but" was the most frequent contrastive DM. "Because" and "by the way" were respectively the only reason and topic-related DMs used by the participants, while "sure" was the most frequent interpersonal DM. In addition, results of the chi-square test revealed that learners significantly employed interpersonal DMs more than the other sub-classes of DMs. Concerning the role of gender in the use of DMs, results demonstrated that females significantly used more DMs compared with the males.
\end{abstract}

Keywords: discourse markers; gender; EFL learners; second language learning; discourse linguistics

\section{Introduction}

Discourse markers (DMs) have a variety of functions in second language (L2) (including EFL) learners' competence. Situational functions, textual cohesion, and conversational fluency are the major aspects that can be facilitated by a good command of DMs. To promote the learning of DMs, language patterns from everyday talks and real contexts should be used to emphasize their practical function and to highlight the contextual appropriateness of DMs. As the literature on DMs shows, many studies have investigated the factors that seem to affect the use of DMs among EFL learners. (e.g., Aijmer, 2002; Archakis, 2001; Chun, 2008; Duran, 2001)

Depending on their L2 level and cultural background, EFL learners may frequently use some DMs while ignoring others. Another factor that hypothetically affects the use of DMs in L2 learning is gender. Some researchers have observed significantly different tendencies among male and female as far as the use of DMs are concerned. (e.g., Eckert \& McConnell, 2003; Escalera, 2006; Kim \& Kang, 2011). A basic problem is that such studies are empirical reports of particular contexts, and their findings have to be put to test in various cultural contexts worldwide.

The purpose of this study is to investigate the use of DMs as used in the spoken language of Iranian advanced EFL learners. The study tries to find the most dominant tendencies in use of DMs in the context and to examine the role of gender on the application of DMs. The framework guiding the study is based on a combination of Fraser's (1999) taxonomy of DMs and Fung's (2003a) category of interpersonal DMs. For the best results, the study relies on a mixed research method.

\section{Review of Literature}

Schiffrin (1987) defines DMs as sequentially dependent elements which bracket units of talk. She believes that DMs 
are practiced in discourse because they present contextual coordinates for utterances. That is, they take part in making the restricted coherence which is collectively built by negotiators in their discourse framework, context, meaning and action during interaction. They make the relation between what is being said to what has already been said, either within a speaker's discourse or across speakers' discourses. Schiffrin (1987) investigated a number of discourse markers: "oh", 'well” (particles), "and", "but", "or", "so", "because" (conjunctions), "now", "the" (time deictics), and "you know", "I mean" (lexicalized clauses) in a thorough study.

Adding to textual cohesion, then, is one of the functions of DMs. Linguistics contend that cohesion is a substantial feature of language skills (Gray \& Cortes, 2011), and second language (L2) researchers try to explore methods through which cohesion can be more efficiently taught to English language learners (see Mahlberg et al, 2004). In L2 teaching, pair-work/group activities can be implemented to encourage learners to interact with each other by engaging in "spontaneous conversations" (Brillanceau, 2005) which help reinforce the use of discourse-pragmatic markers. Intensive activities enhance EFL learners' awareness about proper situations in which DMs should be used.

Terminologically speaking, there is a variety of terms that can refer to DMs, such as "sentence connectives" (Halliday and Hasan, 1976), "discourse particles" (Aijmer 2002; Schourup 1985), "utterance particles" (Luke 1987, 1990), "semantic conjuncts" (Quirk et al., 1985), "pragmatic expressions" (Erman, 1987), "discourse operators" (Redeker, 1991), "continuatives" (Romero Trillo, 1997), "discourse connectives" (Blakemore 1987, 1992), and "discourse markers" (Carter and McCarthy, 2006; Fraser 1990, 1999). This last term is most widely used. Schourup (1999), in his later works, adopted the term discourse marker, as did Blakemore (2002).

Yet, DM classifications and definitions are open to debate. Schourup (1999) and Fung and Carter (2007) have provided a comprehensive list of characteristics for DMs. Schourup (1999) has proposed seven aspects characterizing DMs: connectivity, optionality, non-truth-conditionality, weak clause association, initiality, orality, and multi-categoriality. He claims that the first three are the main characteristics of DMs. Fung and Carter (2007) also have enumerated five criteria which are similar to the characteristics is identified by Schourup, although such criteria relatively diverge from the conventions in defining DMs: position, prosody, multi-grammaticality, indexicality, and optionality.

DMs are not assumed to be perplexing linguistic categories. However, earlier studies on DMs suggest that these categories were previously thought to be complicated. That is why different terminologies, definitions, classifications, and taxonomies have been suggested (Aijmer, 2002; Brinton, 1996; Fraser, 1999; Schiffrin, 1987). Moreover, DMs have been viewed and investigated from many different perspectives because of their multivariate, multifunctional, and multifaceted nature. Presumably, DMs are joined to the absolute side of human communication (Erman, 2001).

Yang (2011) emphasizes the importance of descriptive analyses of how native speakers apply DMs or how non-native speakers use DMs in their attempts to speak a foreign language. However, descriptive analysis employed in several studies shows that such a trend can be categorized into some groups of surveys. Some of the major groups of studies have addressed topics such as the role of DMs, interaction between DMs and other variables, nature and specifications of DMs, the use of DMs in a special context, frameworks for analyzing DMs, and the analysis of a specific discourse marker in a specific situation.

Most studies on DMs, either theoretical or empirical, have investigated the functions of DMs. Despite this large trend of studies, researchers rarely agree on how to exactly determine the functions of DMs. One reason for the difficulty in defining DMs is that the functions of DMs directly depend on speakers' (non-observable) subjectivity or researchers' personal interpretation of utterances. As a result, a considerable magnitude of hypotheses and theories on DMs functions have been examined and proposed in the literature. The functions discussed in previous studies have been obtained from empirical contexts in which a DM is used.

Müller (2005) conducted a comparative study spoken English produced by non-native American speakers and non-native German speakers. Müller provided a comprehensive analysis of the frequencies and functions of four DMs: "so", "well", "you know" and "like". The study was designed and conducted in such a way that it could easily collect comparable data from the participants' discussions on silent movie narratives. In addition, Müller instructionally identified the functions of the four DMs and categorized them into two levels: textual and interactional. The functions of DMs at the textual level were not used for addressing listeners but rather for focusing on lexical expressions, the framework of propositional contents, and the difference between the speaker's voice and reported speech.

DMs functions at the interactional level, however, serves to construct a relationship between speakers and listeners by marking a speech act, a response, an opinion, an evaluation, appeal to the listener, and so on. "So", "you know" 
and "well" were found to have functions at both textual and interactional levels. "Like", on the other hand, functioned only at the textual level. It was suggested that German students used "so", "you know" and "like" less frequently than American students. The same observation held true for "well." Yet, some functions were used only by Americans and some only by Germans.

Wang and Zhu (2005) investigated fifteen types of DMs in the Spoken English Corpus of Chinese Learners (SECCL) and the spoken component of the British National Corpus (BNC). SECCL includes Chinese-speaking, non-native speakers' speeches and utterances, while the British National Corpus contains native speakers' casual talks. As a result of the study, three main differences were found between non-native Chinese speakers and native speakers in terms of using DMs: (a) the non-native speakers and native speakers tended to apply different types of DMs; (b), the non-native speakers used DMs less than native speakers in terms of frequency and type; and (c) the non-native speakers used DMs, such as "and", "but" and "very" and fillers with semantic meaning, such as "I think". Methods used in such studies have highlighted comparability in learner corpus research and the practicality of corpora for investigating DMs.

However, a serious problem in these frames of studies is whether frequency of DMs use could necessarily decide underuse and overuse of DMs. The above studies by Müller (2005) and Wang and Zhu (2005) differed in terms of their range, capacity and research methodology. Müller accumulated two spoken bulks of native speakers and non-native speakers and studied four DMs. Her study involved a qualitative design, which could allow for discussing underuse or overuse entities in two different qualitative frames. On the other hand, Wang and Zhu's relied on a completely quantitative design, which compared a large number of DMs used in two groups with a similar size but with different types. Although this study provided a good statistical perspective into DMs, it failed to investigate the function and use of DMs. In contrast, Müller's study suggested a thorough description of DMs' use.

Jalilifar (2008) studied DMs and their effect on writing skills among university students, applying Schiffrin's (1987) model. Finding of his research indicated that there existed a direct and positive relationship between the quality of the compositions and the frequency of well-functioned DMs. He also concluded that there were statistically significant differences between the use of discourse markers and the quality of composition writing and the more discourse markers are used in essay writing the more cohesive the texts are.

Rahimi and Riasati (2008) conducted a comparative study on the explicit and implicit methods of teaching DMs, their interactions, and effect on learners' speech. Primarily, they explicitly instructed the experimental group for 20 minutes every session. To collect data, they employed the qualitative method of performing semi-structured interviews. Findings revealed that the control group, which received implicit DMs instruction, did not use DMs as frequently as the experimental group did, because the experimental group had received explicit instruction of DMs in their oral production. The results emphasized that explicit teaching could effective influenced in students' use of DMs.

Rahimi and Ghanbari (2011) investigated the relationship between the use of DMs and writing quality in two different kinds of essays (argumentative and expository) in a context of Iranian undergraduate EFL students. He applied a quantitative method of analysis. The results showed that "and" was the most frequently used DM in both kinds of essays, while contrastive and inferential markers were the least frequently used ones. Generally speaking, the average use of DM was significantly higher in argumentative essays. However, the qualitative analysis of the results showed that the use of DMs could not serve as a significant index of the Iranian EFL students writing quality.

Rezaee et al. (2015) investigated the role of gender in the use of four DMs "well", "OK", "you know", and "I mean" in the spoken language of Iranian and English professors. The researchers concluded that there were significant differences in the use of DMs and their pragmatic functions in Iranian and English male and female professors' lectures. They concluded that Iranian and English female professors used the DMs much more frequently compared to the male professors.

\section{Research Questions}

The following questions guided this study:

1. What are the most frequently used discourse markers in the context of the Iranian advanced EFL learners? Is there a statistical difference among the categories of DMs used?

2. Is there a statistically significant difference in terms of gender in the context of the Iranian advanced EFL learners? 


\section{Methodology}

\subsection{Participants}

Forty EFL learners (19 male and 21 females) selected from an English language institute participated in this study. All the participants were native speakers of Persian aged 18-25. The participants were mostly university students majoring in civil engineering, architecture, management and law. They were EFL learners at an advanced level. A placement test had been administered to select these learners for this level, which guaranteed the homogeneity of their proficiency level.

The students studied American English through a speaking-focused course. Permission for data collection was granted from the principal of the institute. Information sheets, reporting the purpose and procedures of this study, were distributed among the classroom teachers. Then an appropriate time was scheduled with the instructors for data collection. The participants were informed that their participation was entirely voluntary and that their participation would not affect their class scores. The participants were also informed that the data would be collected anonymously and kept confidential by the researchers.

\subsection{Observation}

The data were collected from two conversation classes in fall 2016. Classroom discussions were observed overtly and directly and audio recorded through five sessions of the two class time. The discussions were about people's personalities, art and music, social responsibility, fashion, and politics. Specific parts of the interactions were transcribed. Random mistakes and errors committed by participants were not corrected; rather, they were transcribed as they occurred. Each session lasted 90 minutes. The collected data through class observations were then classified, tabulated and interpreted.

\subsection{Theoretical Framework}

Fraser's (1999) introduced a taxonomy of DMs. His taxonomy encompasses two types of DMs. First, those that relate the explicit interpretation conveyed by the second segment with some aspect associated with the first segment; and those that relate the topic of the second segment to that of the first segment. According to Fraser, the first type (message-related) includes the following subcategories: contrastive, elaborative, inferential, and reason discourse markers. The first subcategory of discourse markers includes contrastive markers. Contrastive markers show that the explicit interpretation of the second sentence contrasts with an interpretation of the first sentence. The elaborative marker is considered to be the second subcategory. It signals a quasi-parallel relationship between the sentences. Inferential markers, too, shape as the third subcategory. It shows that a following sentence is a conclusion derived from the preceding sentence. A reason DM indicates that the following sentence is a reason for the preceding sentence.

Table 1. A summarized Version of Fraser's Taxonomy of Discourse Markers and Fung's Category of Interpersonal Discourse Markers

\begin{tabular}{|c|c|c|c|}
\hline & $\begin{array}{l}\text { Message-related } \\
\text { markers }\end{array}$ & Contrastive & $\begin{array}{l}\text { but, however, in comparison to, on the contrary, } \\
\text { conversely, instead, despite, nonetheless, still }\end{array}$ \\
\hline & & Elaborative & $\begin{array}{l}\text { and, besides, furthermore, more to the point, } \\
\text { parenthetically, to cap it all off, analogously, } \\
\text { correspondingly, otherwise }\end{array}$ \\
\hline & & Inferential & $\begin{array}{l}\text { so, accordingly, of course, as a consequence, for } \\
\text { this/that reason, therefore, thus, in this/that case }\end{array}$ \\
\hline & & Reason & after all, because, since \\
\hline $\begin{array}{l}\text { Fraser s } \\
\text { Taxonomy } \\
(1999)\end{array}$ & $\begin{array}{l}\text { Topic-related } \\
\text { markers }\end{array}$ & & $\begin{array}{l}\text { back to my original point, before I forget, by the } \\
\text { way, incidentally, with regard to }\end{array}$ \\
\hline Fung (2003) & $\begin{array}{l}\text { interpersonal } \\
\text { discourse markers }\end{array}$ & & $\begin{array}{l}\text { See, you see, you know, listen. well, really, I } \\
\text { think, obviously, absolutely, basically, actually }\end{array}$ \\
\hline
\end{tabular}

Fraser (1999) considers the second type of DMs to be topic-related ones, explaining in these structures the first segment contributes to the topic presented by the second segment. To analyze interpersonal DMs, Fung's (2003a) category of interpersonal discourse markers was employed. Fung's category is useful in marking shared knowledge 
between the participants and marking the attitude of the participants towards the propositional content of discourse segments. Fung's category is typically used in spoken rather than in written discourse. Table 1 shows the message-related and topic-related markers, as well as DMs.

\subsection{Data Analysis}

The data were analyzed quantitatively through dimensions of descriptive statistics. Following that, chi-square test was conducted to investigate whether there was any significant difference between the frequencies of DMs used by the learners. Chi-square test was also run to find any difference between male and female participants in terms of the frequency of their DMs use.

\section{Findings and Results}

To answer the first research question, which tried to find the most frequently used DM by Iranian Advanced EFL Learners, first the frequency of DMs was calculated (see Table 2):

Table 2. Frequency of the Discourse Markers

\begin{tabular}{|c|c|c|c|c|c|}
\hline & & Frequency & Percent & Valid Percent & Cumulative Percent \\
\hline \multirow{3}{*}{ Elaborative } & and & 178 & 83.6 & 83.6 & 83.6 \\
\hline & I mean & 22 & 10.3 & 10.3 & 93.9 \\
\hline & otherwise & 13 & 6.1 & 6.1 & 100.0 \\
\hline \multirow{5}{*}{ Contrastive } & Total & 213 & 100.0 & 100.0 & \\
\hline & but & 22 & 45.8 & 45.8 & 45.8 \\
\hline & In comparison with & 13 & 27.1 & 27.1 & 72.9 \\
\hline & however & 13 & 27.1 & 27.1 & 100.0 \\
\hline & Total & 48 & 100.0 & 100.0 & \\
\hline \multirow{5}{*}{ Inferential } & therefore & 11 & 20.4 & 20.4 & 20.4 \\
\hline & So & 12 & 22.2 & 22.2 & 42.6 \\
\hline & of course & 14 & 25.9 & 25.9 & 68.5 \\
\hline & then & 17 & 31.5 & 31.5 & 100.0 \\
\hline & Total & 54 & 100.0 & 100.0 & \\
\hline \multirow{2}{*}{ Reason } & because & 12 & 100.0 & 100.0 & 100.0 \\
\hline & Total & 12 & 100.0 & 100.0 & \\
\hline \multirow{2}{*}{ Topic related } & By the way & 9 & 100.0 & 100.0 & 100.0 \\
\hline & Total & 100.0 & 100.0 & 100.0 & \\
\hline \multirow{16}{*}{ Interpersonal } & well & 16 & 4.6 & 4.6 & 4.6 \\
\hline & look & 3 & 0.9 & 0.9 & 5.5 \\
\hline & really & 11 & 3.2 & 3.2 & 8.7 \\
\hline & I think & 32 & 9.2 & 9.2 & 17.9 \\
\hline & actually & 19 & 5.5 & 5.5 & 23.4 \\
\hline & exactly & 30 & 8.7 & 8.7 & 32.1 \\
\hline & $\mathrm{Ok}$ & 45 & 13.0 & 13.0 & 45.1 \\
\hline & right & 23 & 6.6 & 6.6 & 51.7 \\
\hline & great & 19 & 5.5 & 5.5 & 57.2 \\
\hline & sure & 47 & 13.6 & 13.6 & 70.8 \\
\hline & yeah & 36 & 10.4 & 10.4 & 81.2 \\
\hline & like & 12 & 3.5 & 3.5 & 84.7 \\
\hline & absolutely & 5 & 1.4 & 1.4 & 86.1 \\
\hline & you know & 16 & 4.6 & 4.6 & 90.8 \\
\hline & yes & 32 & 9.2 & 9.2 & 100 \\
\hline & Total & 346 & 100.0 & 100.0 & \\
\hline
\end{tabular}

As Table 2 shows, "and" was the most frequent elaborative DM (83.6\%) used by the participants. The results also revealed that "but" was used as the most favored contrastive DM (45.8\%). Among the inferential DMs, "then" (31.5\%) was used more than the other choices. Additionally, "because" was the only reason DM used by the participants. The 
findings also revealed that the participants used only one topic-related DM, "by the way". Table 2 also shows that "sure" $(13.6 \%)$ was the most frequent interpersonal DM used by the participants. Table 3 illustrates the frequency of DM in different discourse marker sub-classes.

Table 3. Frequency of the Used Markers in Different Sub-classes of the Discourse Markers

\begin{tabular}{llrrrc}
\hline & Frequency & Percent & Valid Percent & Cumulative Percent \\
\hline \multirow{4}{*}{ Valid } & 213 & 31.2 & 31.2 & 31.2 \\
& Elaborative & 48 & 7.0 & 7.0 & 38.3 \\
& Contrastive & 12 & 1.8 & 1.8 & 40.0 \\
& Reason & 54 & 7.9 & 7.9 & 47.9 \\
& Inferential & 9 & 1.3 & 1.3 & 49.3 \\
& Topic related & 346 & 50.7 & 50.7 & \\
& Interpersonal & 682 & 100.0 & 100.0 & \\
& Total & 682.0 &
\end{tabular}

Based on the findings in Table 3, interpersonal markers were the most frequently used ones $(50.7 \%)$. Elaborative markers with $31.2 \%$ of cases were the second most frequent DMs, followed by inferential DMs $(7.9 \%)$ and contrastive DMs (7.0\%). The results also showed that reason markers covered $1.8 \%$ of the distribution. Finally, topic-related markers $(1.3 \%)$ found to be the least frequent DMs used by the learners. To discover any significant difference between the frequencies of DM used by the learners, chi-square test was conducted (see Table 4).

Table 4. Chi-Square Test to Examine the Difference between the Frequencies of Discourse Markers

\begin{tabular}{lc}
\hline & Category \\
\hline Chi-Square & $818.264^{\mathrm{a}}$ \\
$\mathrm{df}$ & 5 \\
Asymp. Sig. & .000 \\
\hline
\end{tabular}

Results of the chi-square test revealed that the difference between the frequencies of DMs was significant (sig. $=.00$, $p<.05)$. As Table 3 shows, the learners significantly used interpersonal DMs (50.7\%) more than the other sub-classes. To investigate the role of gender in the use of DMs by Iranian EFL learners, chi-square test was conducted (see results in Table 5).

Table 5. Frequency of the Discourse Markers Used by Males and Females

\begin{tabular}{|c|c|c|c|c|c|c|c|c|}
\hline \multicolumn{9}{|c|}{ Gender * Category Crosstabulation } \\
\hline \multirow[t]{3}{*}{ Count } & & \multirow{2}{*}{\multicolumn{6}{|c|}{ Category }} & \multirow{3}{*}{ Total } \\
\hline & & & & & & & & \\
\hline & & Elaborative & Contrastive & Reason & Inferential & Topic related & Interpersonal & \\
\hline \multirow{2}{*}{ Gender } & Male & 21 & 16 & 2 & 17 & 4 & 123 & 183 \\
\hline & Female & 192 & 32 & 10 & 37 & 5 & 223 & 499 \\
\hline Total & & 213 & 48 & 12 & 54 & 9 & 346 & 682 \\
\hline
\end{tabular}

According to Table 5, female participants used all the categories of DMs more than male participants. To explore if there was any significant difference between males and females in terms of the frequency of DMs, chi-square test was run (see Table 6).

The results of the chi-square test indicated that the difference between male and female participants in terms of the frequency of DMs was significant (sig. $=.00, p<.05$ ). Based on the results (Table 5), the female learners used more DMs $(f=499)$ compared with the male participants $(f=183)$, in general. The results also indicated that the females significantly used more elaborative ( $f=192)$, contrastive $(f=32)$, reason $(f=10)$, inferential $(f=37)$, topic-related ( $f$ $=5$ ), and interpersonal discourse markers $(f=223)$, compared with the males. Providing graphic image of the results, Figure 1 illustrates the frequency of the DMs in both groups. 
Table 6. Chi-Square Test to Examine the Difference between Males and Females in terms of the Frequency of Discourse Markers

\begin{tabular}{|c|c|c|c|}
\hline \multicolumn{4}{|c|}{ Chi-Square Tests } \\
\hline & Value & $\mathrm{df}$ & Asymp. Sig. (2-sided) \\
\hline Pearson Chi-Square & $48.327^{\mathrm{a}}$ & 5 & .000 \\
\hline Likelihood Ratio & 54.228 & 5 & .000 \\
\hline Linear-by-Linear Association & 39.604 & 1 & .000 \\
\hline $\mathrm{N}$ of Valid Cases & 682 & & \\
\hline
\end{tabular}

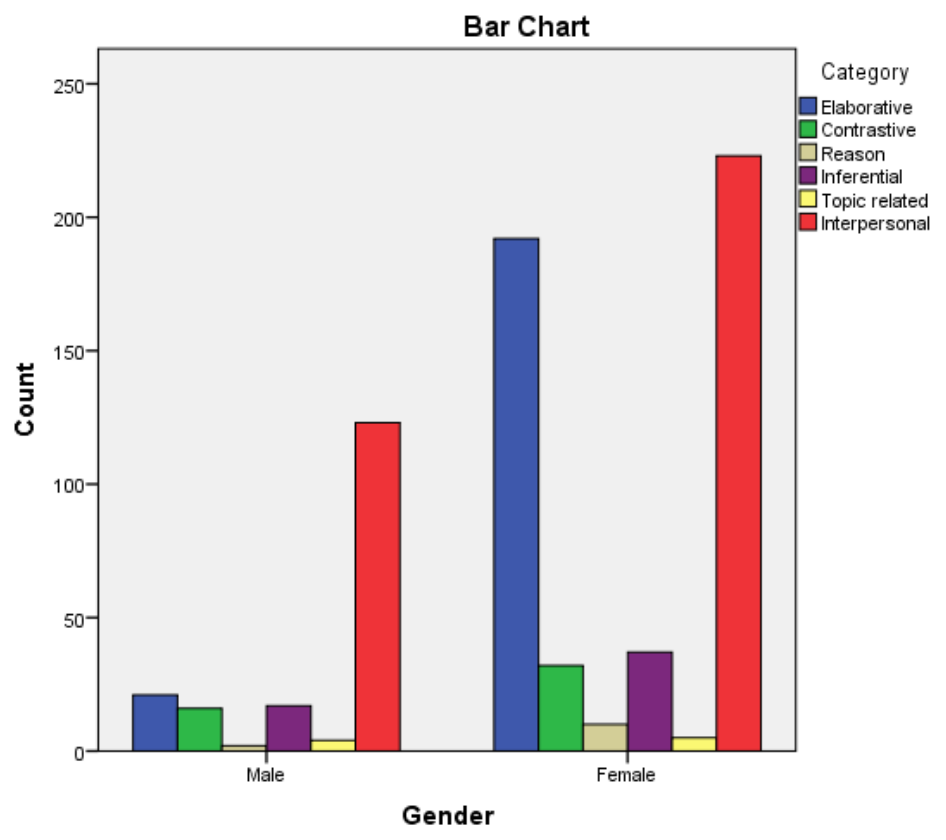

Figure 1. Bar Graph of the Frequency of the Discourse Markers Used by Males and Females

\section{Discussion and Conclusion}

The present study sought to find the most frequently used DMs and to explore the impact of gender on the use of DMs in a context of Iranian advanced EFL learners. The research questions of the study were answered in light of the findings of the study in the following. The results of the frequency calculation and chi-square test revealed that interpersonal DMs were employed most frequently by Iranian advanced EFL learners, followed by elaborative, inferential, contrastive, reason, and finally topic-related DMs.

According to the achieved results, it was found that "and" was the most frequent elaborative DM used by the learners. In addition, the results indicated that "but" was the most frequently used contrastive discourse marker and "then" was the most used inferential DMs. Based on the results, "because" was the only reason DM used by the learners. The results also showed that the learners used only one topic-related DM, "by the way". The results also showed that "sure" was the most frequent interpersonal DM used by the learners.

The results of the frequency calculation and chi-square test showed that the female learners significantly used all sub-classes of DMs (elaborative, contrastive, reason, inferential, topic-related, and interpersonal discourse markers) more than the males. There might be various explanations regarding the findings. For instance, Mason (2008) explained that memory load may lead one to make use of discourse markers in one's speech. Females used more DMs in the present study because they had possibly encountered more memory load.

Another possible explanation is that females were emotionally different from males (See Karimnia, 2003; Nouraey \& Karimnia, 2016). In this regards, Kim and Kang (2011) investigated the emotional aspect of gender in speakers' choice of DMs. They indicated that "women respond more emotionally than men, and use more discourse markers 
than them" (ibid., p. 31). Kim and Kang (2011) also argued that the type of speech determines males' and females' choice of DMs. Kim and Kang (2011) state that "there are differences between men and women's private speech, especially discourse markers" (p. 32). Mei (2006) also believes that "in oral English, men and women speak English in different ways based on different employment of discourse markers. Women generally discuss their personal feelings more than men. Men appear to prefer non-personal topics such as sport and news" (ibid., 66-67).

The results of this study were also in line with Rezaee and colleagues' (2015) observations. They conducted an empirical study in Iranian EFL contexts to observe the role of gender in the use of four DMs. According to the results, Iranian and English female professors used the four discourse markers much more frequently and also employed a wider range of the functions of the discourse markers compared to the male professors.

Winkler (2008, p. 69) approached gender from a broader perspective, stating that "there is a great difference between the amount and also type of discourse markers used by females and males". Concerning the pragmatic function of DMs, Matei (2011, p. 219) maintains that "variables like gender influence the main pragmatic functions that literature has ascribed to markers". According to Matei (ibid.), "It is the core pragmatic meaning of discourse markers that establish a general pattern of use". Concerning the role of gender in the use of DMs by Iranian learners, Alami and Sabbah (2012) explain that the function of DMs affects the type of markers used by different genders in their discourse. In line with findings of the present study, Alami and Sabbah (2012), more specifically, mention that "The difference between Persian men-women discourse in terms of DMs usage is of functional type rather than quantitative where the gender of the speaker does seem to be an influencing factor in DMs usage" (p. 157).

\section{References}

Aijmer, K. (2002). English discourse particles: Evidence from a corpus. Amsterdam/Philadelphia: John Benjamins. https://doi.org/10.1075/scl.10

Alami, M., \& Sabbah, M. (2012). Gender and discourse difference: An investigation of discourse markers in Persian male-female casual conversation. Persian Language Scientific Research Quarterly, 10(1), 1-17.

Archakis, A. (2001). On discourse markers: Evidence from modern Greek. Journal of pragmatics, 33(8), 1235-1262. https://doi.org/10.1016/S0378-2166(00)00054-0

Brillanceau, D. (2005). Spontaneous conversations: a window into learners' autonomy. Connecting Research and Practice, 8, 22-25.

Brinton, L. J. (1996). Pragmatic markers in English: Grammaticalization and discourse functions. Berlin and New York: Mouton de Gruyter. https://doi.org/10.1515/9783110907582

Carter, R.T. (2007). Racism and psychological and emotional injury: Recognizing and assessing race-based traumatic stress. The Counseling Psychologist, 35, 13-105. https://doi.org/10.1177/0011000006292033

Chun, C. X. (2008). An investigation of discourse markers across gender in non- English majors' argumentative writings in English. Unpublished MA Thesis. Xinjiang Normal University.

Eckert, P., \& McConnell-Ginet, S. (2003). Language and Gender. Cambridge University Press. https://doi.org/10.1017/cbo9780511791147

Erman, B. (1987). Pragmatic expressions in English: A study of you know, you see, and I mean in face-to-face conversation. Stockholm. Sweden: Almqvist \& Wiksell International.

Erman, B. (2001). Pragmatic markers revisited with a focus on you know in adult and adolescent talk. Journal of Pragmatics, 3, 37-59. https://doi.org/10.1016/S0378-2166(00)00066-7

Escalera, E. A. (2006). Gender difference in children's use of discourse markers: Separate worlds or different contexts? Journal of Pragmatics, 41, 2479-2495. https://doi.org/10.1016/j.pragma.2006.08.013

Fraser, B. (1999). What are discourse markers? Journal of Pragmatics, 31, 931-952. https://doi.org/10.1016/S0378-2166(98)00101-5

Fung, A. (2003a). Deliberative democracy and international labor standards. Governance, 16(1), 51-71. https://doi.org/10.1111/1468-0491.t01-1-00204

Halliday, M.A.K., \& Hnsn, N. (1976). Cohesion in English. London: Longman.

Jalilifar, A. (2008). Discourse markers in composition writings: The case of Iranian learners of English as a foreign language. English Language Teaching Journal, 1(2), 114-122. https://doi.org/10.5539/elt.v1n2p114 
Karimnia, A. (2003). The effect of speaker's and listener's gender on listening comprehension. Indian Journal of applied linguistics, 29(1), 99-107.

Kim, H., \& Kang, B. (2011). Gender and usage of discourse markers in spoken Korean. Proceedings of the $16^{\text {th }}$ Conference of Pan-Pacific Association of Applied Linguistics, 5, 30-31.

Mahlberg, R., Kunz, D., Sutej, I., Kuhl, K.P., \& Hellweg, R. (2004). Melatonin treatment of day-night rhythm disturbances and sundowning in Alzheimer disease: An open-label pilot study using actigraphy. Clin Psychopharmacol, 24, 456-459. https://doi.org/10.1097/01.jcp.0000132443.12607.fd

Matei, M. (2011). The influence of age and gender on the selection of discourse markers in casual conversations. Philology and Cultural Studies, 4(53), 213-220.

Mei, L. Y. (2006). Research on gender differences in the employment of discourse markers. Unpublished MA Thesis, Chengdu University of Technology.

Muller, S. (2005). Discourse markers in native and non-native English Discourse. Amsterdam/Philadelphia: John Benjamins. https://doi.org/10.1075/pbns.138

Nouraey, P., \& Karimnia, A. (2016). The impact of rhythm and gender on spelling output of Iranian EFL learners: A cross-sectional study. Khazar Journal of Humanities and Social Sciences, 19(2), 53-63.

Johnson, R. B., Meeker, K., Loomis, E., \& Onwuegbuzie, A. J. (2007). Toward a Definition of Mixed Methods Research. Journal of Mixed Methods Research, 2, 112-130. https://doi.org/10.1177/1558689806298224

Rahimi, A., \& Ghanbari, N. (2011). The impact of teachers' scaffolding on Iranian high school students' reading comprehension. Social and Behavioral Sciences, 28, 1072-1076. https://doi.org/10.1016/j.sbspro.2011.11.193

Rahimi, F., \& Riasati, J. (2012). The effect of explicit instruction of discourse markers on the quality of oral output. International Journal of Applied Linguistics \& English Literature, 11(3), 65-79.

Redeker, G. (1991). Review article: Linguistic markers of discourse structure. Linguistics, 29(6), 1139-1172.

Rezaee, M., Aghagolzadeh, F., \& Birjandi, P. (2015). The effect of lecturers' gender on the use of discourse markers. International Journal of Research Studies in Language Learning, 4(2), 69-87. https://doi.org/10.5861/ijrsll.2014.900

Romero Trillo, J. (1997). Your attention, please. Pragmatic mechanisms to obtain the addressee's attention in English and Spanish conversations. Journal of Pragmatics, 28, 205-221. https://doi.org/10.1515/cllt-2014-0026

Schiffrin, D. (1987). Discourse markers. Cambridge: Cambridge University Press. https://doi.org/10.1017/CBO9780511611841

Schourup, L. (1985). Common discourse particles in English conversation. New York: Garland.

Wang, L. F., \& Zhu, J. H. (2005). A study on the use of discourse markers in Chinese students' oral English. Foreign Languages Research, 3, 40-48.

Winkler, E. G. (2008). A gender-based analysis of discourse markers in Limonese creole. Language \& Culture, 8 , 53-72.

Yang, H. (2011). Investigating discourse markers in pedagogical settings: A literature review. ARECLS, 8, 95-108. 